\title{
Produção e aceitabilidade de suco composto: uma alternativa tecnológica para a cadeia produtiva do milho
}

O milho (Zea mays L.) é considerado mundialmente um dos cereais mais importantes devido ao seu elevado potencial produtivo, composição química e valo nutritivo. É um grão que possui elevada aceitação no mercado, devido possuir várias formas de uso e possibilidade de combinações tais como sobremesa individual ou em forma de bolos, sorvetes, sucos, etc. O objetivo deste estudo foi de formular e realizar a análise sensorial de sucos compostos a partir do milho produzido no município de Parauapebas-PA. Para obtenção dos sucos de milho, foram elaboradas as seguintes formulações: suco de milho natural (F1: $21 \%$ de grãos: $33 \%$ de água); suco de milho com leite de soja (F2: $21 \%$ de grãos: $33 \%$ de leite de soja); suco de milho com leite bovino (F3: $21 \%$ de grãos: $33 \%$ de leite bovino). As análises microbiológicas realizadas nos grãos e nos sucos elaborados foram fungos filamentosos e leveduras, Salmonella spp., Coliformes a 35 e a $45^{\circ} \mathrm{C}$ e Staphylococcus coagulase positiva. Para a avaliação sensorial foram realizados os testes de aceitabilidade com escala hedônica estruturada para os seguintes parâmetros: aparência, aroma, sabor e impressão global; assim como o índice de aceitação e a intenção de compra dos produtos. Os resultados das análises sensoriais dos grãos e dos produtos elaborados foram submetidos à análise de variância através do teste de Tukey a $5 \%$ de probabilidade. Os resultados verificados nos grãos de milho e nos produtos elaborados, indicaram ausência de microrganismos para $25 \mathrm{~g}$ de amostra. Através dos resultados sensoriais observou-se que os sucos de leite possuem maior aceitabilidade pelos provadores do que o suco natural, e o suco com soja. Todos os parâmetros avaliados no teste de aceitação sensorial obtiveram notas médias entre 6 (gostei ligeiramente) e 7 (gostei moderadamente), indicando aceitação e intenção de compra dos produtos por parte dos provadores. De acordo com os resultados obtidos, os produtos podem se tornar uma alternativa tecnológica para a cadeia produtiva do milho, além de uma opção de geração de renda aos agricultores familiares.

Palavras-chave: Processamento; Análise sensorial; Agricultores familiares.

\section{Production and acceptability compound juice: an alternative technology for the production chain corn}

\begin{abstract}
Corn (Zea mays L.) is considered worldwide as one of the most important cereals due to its high productive potential, chemical composition and nutritional value. It is a grain that has high acceptance in the market, due to its various forms of use and the possibility of combinations such as individual dessert or in the form of cakes, ice cream, juices, etc. The aim of this study was to formulate and carry out the sensory analysis of compound juices from corn produced in the municipality of Parauapebas-PA. To obtain corn juices, the following formulations were prepared: natural corn juice (F1: $21 \%$ of grains: $33 \%$ of water); corn juice with soy milk (F2: $21 \%$ of grains: $33 \%$ of soy milk); corn juice with bovine milk (F3: $21 \%$ of grains: $33 \%$ of bovine milk). The microbiological analyzes performed on the grains and in the elaborated juices were filamentous fungi and yeasts, Salmonella spp., Coliforms at 35 and $45^{\circ} \mathrm{C}$ and positive coagulase Staphylococcus. For the sensory evaluation, acceptability tests were carried out with a hedonic scale structured for the following parameters: appearance, aroma, flavor and global impression; as well as the acceptance index and the purchase intention of the products. The results of sensory analysis of grains and elaborated products were subjected to analysis of variance through the Tukey test at $5 \%$ probability. The results verified in the corn grains and in the elaborated products, indicated absence of microorganisms for $25 \mathrm{~g}$ of sample. Through the sensory results it was observed that milk juices have greater acceptability by tasters than natural juice, and juice with soy. All parameters evaluated in the sensory acceptance test obtained average scores between 6 (slightly liked) and 7 (moderately liked), indicating acceptance and intention to purchase the products by the tasters. According to the results obtained, the products can become a technological alternative for the corn production chain, as well as an option to generate income for family farmers.
\end{abstract}

Keywords: Processing; Sensory analysis; Family farmers.

Topic: Tecnologia de Alimentos

Reviewed anonymously in the process of blind peer.
Received: 02/03/2020

Approved: 11/06/2020
Rodrigo de Souza Mota

Universidade Federal Rural da Amazônia, Brasil

http://lattes.cnpq.br/0329344212994088

rodrigodemota@gmail.com

Igor Vinícius de Oliveira

Universidade Federal do Sul e Sudeste do Pará, Brasil

http://lattes.cnpq.br/1133025899150852

http://orcid.org/0000-0003-4218-5587

igor.oliveira@unifesspa.edu.br

João Paixão dos Santos Neto

Instituto Nacional de Investigação de Portugal, Brasil

http://lattes.cnpq.br/2828947517814190

joaopaixaoneto@gmail.com

d

DOI: 10.6008/CBPC2237-9290.2020.002.0001

\author{
Fabio Israel Martins Carvalho (iD) \\ Universidade Federal Rural da Amazônia, Brasil \\ http://lattes.cnpq.br/8221002637257793 \\ http://orcid.org/0000-0002-8995-2141 \\ fabioimc@yahoo.com.br \\ Priscilla Andrade Silva (iD) \\ Universidade Federal Rural da Amazônia, Brasil \\ http://lattes.cnpq.br/7666887041806711 \\ http://orcid.org/0000-0002-2774-3192 \\ prisciandra@yahoo.com.br
}

\section{Referencing this:}

MOTA, R. S.; OLIVEIRA, I. V.; SANTOS NETO, J. P.; CARVALHO, F. I. M.; SILVA, P. A.. Produção e aceitabilidade de suco composto: uma alternativa tecnológica para a cadeia produtiva do milho. Natural Resources, v.10, n.2, p.1-10, 2020. DOI:

http://doi.org/10.6008/CBPC2237-9290.2020.002.0001 


\section{INTRODUÇÃO}

Originário nas Américas, no México e no Sudoeste dos Estados Unidos especificamente, o milho (Zea mays L.) é uma das plantas de maior eficiência comercial do mundo (NEUMANN et al., 2006). Ao logo da história, a produção do milho vem crescendo anualmente, isso ocorre principalmente devido às atividades de avicultura e suinocultura, onde o milho pode ser consumido diretamente ou ser utilizado na fabricação de rações e destinado ao consumo de animais. Na alimentação humana, o milho é comumente empregado na forma in natura, como milho verde, e na forma de subprodutos, como pão, farinhas e massas (MARCHI, 2008).

O milho é importante para o comercio nacional por ser típico de determinadas regiões, utilizado nas refeições, em épocas festivas e culturais no preparo de derivados, complemento e consumo humano, além de ser uma alternativa de grande valor econômico para médios e grandes agricultores, responsáveis pela inserção do produto no mercado (FAO, 2018). Isso devido a diversos fatores: demanda pelo produto in natura após cozimento da espiga, ou o preparo de pratos como pamonha, curau, bolos, sorvetes e outros, alcançando maior valor de comercialização quando comparado com o milho destinado a grãos (EMBRAPA, 2009).

Antes de ser descoberta a importância alimentícia do milho, a espécie era cultivada em jardins europeus (BORGES et al., 2006). No Brasil, a importância do milho na alimentação humana varia de região, devido em determinadas regiões o maior consumo do grão e seus derivados ser realizado por famílias de baixa renda e por ser tradicional em culinárias de algumas culturas, como dos nordestinos. Mundialmente, para os mexicanos, por exemplo, o uso desse cereal e seus derivados na sua culinária é uma rica fonte de energia para a população (GONÇALVES et al., 2005).

Com o aumento do mercado e a busca por praticidade e rapidez das pessoas na vida moderna, fez com que a indústria direcionasse seus esforços para diversificar a produção de seus produtos (PALLET et al., 2005). Dessa forma, as frutas que eram consumidas apenas in natura, passaram a ser consumidas das mais variadas formas possíveis como: polpa, conserva, produtos destilados, sorvetes, refrigerantes, confeitos, drinques, néctares, refrescos, barra de serreais, petiscos, entre outros (PEREIRA, 2006).

A expansão mundial do consumo de bebida pronta, ocorreu devido os mesmos oferecerem saúde, conveniência, sabor, inovação e prazer. O suco de laranja pronto para beber é um dos sucos mais vendidos no Brasil. Os sucos devem atender à legislação específica, estando de acordo com definição, classificação, registro, padronização e requisitos de qualidade, devendo também atender à legislação sobre rotulagem de alimentos embalados (PAVAN et al., 2006). A legislação brasileira na área de alimentos é regida pelo Ministério da Saúde, por intermédio da Agência Nacional de Vigilância Sanitária (ANVISA) e pelo Ministério da Agricultura, Pecuária e Abastecimento (MAPA) (ANVISA, 2002).

Segundo a legislação brasileira, os sucos são caracterizados em cinco grupos: I) sucos naturais: elaborados diretamente da transformação da própria fruta; II) sucos em pó: produzidos por um processo de desidratação; III) sucos concentrados: suco natural desidratado a fim de torná-lo mais concentrado e denso; 
IV) sucos prontos para beber: fabricados mediante a composição do extrato de suco, da água e de uma série de aditivos; V) sucos de polpa: caracteriza-se pela ausência de qualquer processo químico e industrial para a preservação, máxima possível, de todas as propriedades organolépticas das frutas (ROSA et al., 2006).

As bebidas são regulamentadas pela Lei no 8.918, de 14 de julho de 1994, do MAPA, e regida pelo Decreto no 2.314, de 4 de setembro de 1997, que dispõe sobre a padronização, a classificação, o registro, a inspeção, a produção e a fiscalização de bebidas (MAPA, 1997). Posteriormente, o Decreto no 3.510, de 16 de junho de 2000, alterou dispositivos do Decreto no 2.314, de 1997 (MAPA, 1997).

A rotulagem dos sucos de fruta prontos para beber deve atender às exigências da Anvisa sobre rotulagem de alimentos embalados, conforme os Regulamentos Técnicos da Resolução da Diretoria Colegiada no 259, de 20 de setembro de 2002, sobre rotulagem de alimentos embalados, a RDC no 360, de 23 de dezembro de 2003, sobre rotulagem nutricional de alimentos, a Portaria no 27 , de 13 de janeiro de 1998, referente à informação nutricional complementar, a RDC no 359, de 23 de dezembro de 2003, sobre porções de alimentos embalados para fins de rotulagem nutricional, e a Lei no 10.674, de 16 de maio de 2003, que obriga todos os produtos alimentícios comercializados a informar sobre a presença de glúten (ANVISA,2002).

Historicamente, a agricultura familiar no Brasil passou a ter reconhecimento após o final da ditadura militar e a retomada dos movimentos sociais, o engajamento dos intelectuais e mediadores que começaram um debate sobre o tem e a criação de políticas públicas e programas sociais que facilitaram a aquisição de financiamentos (KITAMURA et al., 2002).

A agricultura familiar está diretamente ligada a produção do milho em várias regiões do Brasil, e é sempre lembrada por sua importância na produção de alimentos, especialmente voltada para o consumo interno, ou seja, concentra mais nas funções de caráter social do que as econômicas, tendo em vista sua menor produtividade e incorporação tecnológica (STRIEDER, 2006). Entretanto, é necessário destacar que a produção familiar, além de fator redutor do êxodo rural e fonte de recursos para as famílias com menor renda, também contribui expressivamente para a geração de riqueza, considerando a economia não só do setor agropecuário, mas do próprio país (WANDERLEY, 2009).

O presente estudo teve como finalidade desenvolver diferentes formulações artesanais de suco de milho (sucos de milho, natural, com leite e com soja) a partir do milho e avaliar as características sensoriais dos produtos, produzidos a partir dos grãos de milho híbrido duplo BR 205 Embrapa, cultivados pelo Centro Tecnológico de Agricultura Familiar do município de Parauapebas/PA (CETAF-Parauapebas), que atendam ao requerimento de aceitação pelo público considerando-se, daí a utilização do milho como uma alternativa para melhor aproveitamento tecnológico dessa matéria-prima, com agregação de valor econômico para os grãos produzidos na região, gerando renda para as populações assistidas pelo mesmo. 


\section{MATERIAIS E MÉTODOS}

\section{Material}

As espigas de milho da cultivar do tipo hibrido duplo BR 205 Embrapa, desenvolvida pela Empresa Brasileira de Pesquisa Agropecuária (EMBRAPA) foram coletadas no Centro Tecnológico de Agricultura Familiar de Parauapebas/PA, com as seguintes coordenadas geográficas: 06 03' 30" de latitude Sul e 49은 15" de longitude a Oeste colhidos aos 3 meses após plantio. Para a produção dos sucos de milho (natural, com leite soja e com leite bovino) foram utilizadas as seguintes matérias-primas: leite de soja, leite bovino e açúcar, comercializados nos supermercados de Parauapebas/PA e o milho coletado no CETAF (Centro Tecnológico de Agricultura Familiar de Parauapebas/PA).

\section{Métodos}

Foram elaborados os produtos, suco de milho natural, suco de milho com leite de soja, suco de milho com leite bovino, foram desenvolvidos na Universidade Federal Rural da Amazônia, no Campus de Parauapebas, Pará, localizada nas coordenadas geodésicas 4951'19”W latitude, $06^{\circ} 12^{\prime} 58^{\prime \prime S}$ longitude, com altitude de 197 m com o auxílio do GPS portátil (Modelo eTrex 10, Marca Garmin), assim como todas as análises físico-químicas e sensorial. O período de realização do trabalho foi de março a julho de 2019 . Para as formulações dos sucos de milho natural, suco de milho com leite de soja e suco de milho com leite bovino, foram realizados vários testes com diferentes concentrações de cada matéria prima empregada.

\section{Processo de obtenção dos grãos do milho}

As espigas sem a palha selecionadas foram lavadas, sanitizadas por imersão em solução com hipoclorito de sódio ( $\mathrm{NaCl}$ ) (200 mg/L) durante 15 minutos e novamente imersos em água por 15 minutos, separadamente. Em seguida, as amostras dos grãos foram manualmente separadas das espigas, e embaladas em sacos plásticos de polietileno de $1 \mathrm{Kg}$, congeladas e armazenadas a -20 으 para serem utilizada nas análises físico-químicas e sensoriais no processamento do milho.

\section{Processamento dos produtos de milho}

Na Figura 1, através do fluxograma, podem ser visualizadas as etapas realizadas no processamento dos sucos. Foram elaboradas as seguintes formulações: suco de milho natural (F1: 21\% de grãos: 33\% de água); suco de milho com leite de soja (F2: $21 \%$ de grãos: $33 \%$ de leite de soja); suco de milho com leite bovino (F3: 21\% de grãos: 33\% de leite bovino). Em seguida, as misturas foram homogeneizadas por 5 minutos, sobre vigorosa agitação e filtradas.

Para as formulações dos sucos (F1, F2 e F3) foi acrescida em função do teor de sólidos solúveis, segundo o cálculo, a quantidade de açúcar suficiente para elevar o teor de sólidos para 20Brix por balanço de massa. Os sucos foram coccionados a $100^{\circ} \mathrm{C}$ por $30 \mathrm{~min}$, seguidos de resfriamento a $25^{\circ} \mathrm{C}$, e novamente homogeneizado por 5 min e filtrados, e pasteurizados $\left(90^{\circ} \mathrm{C}\right.$ por 30 segundos). Envasados e armazenados sob 
refrigeração a 8ำ até o momento das análises microbiológicas e sensoriais.

Calculou-se a quantidade de sacarose suficiente para elevar o teor de sólidos solúveis dos sucos para 20Brix, utilizando-se o cálculo de balanço de massa a seguir: $\mathrm{M}_{\mathrm{g}} \times{ }^{\circ} \mathrm{Brix}_{\mathrm{g}}+\mathrm{M}_{\mathrm{a}} \times{ }^{\circ} \mathrm{Brix} \mathrm{x}_{\mathrm{a}}=\mathrm{M}_{\text {produto }} \times{ }^{\circ} \mathrm{Bri} \mathrm{x}_{\text {produtos, }}$ onde: $\mathrm{M}_{\mathrm{g}}=$ massa dos grãos, ${ }^{\circ}$ Brix $\mathrm{g}_{\mathrm{g}}={ }^{\circ}$ Brix dos grãos, $\mathrm{M}_{\mathrm{a}}=$ massa de açúcar, ${ }^{\circ}$ Brix ${ }_{\mathrm{a}}={ }^{\circ}$ Brix do açúcar, $\mathrm{M}_{\mathrm{p}}=$ massa do produto, ${ }^{\circ}$ Brix ${ }_{p}={ }^{\circ}$ Brix do produto.

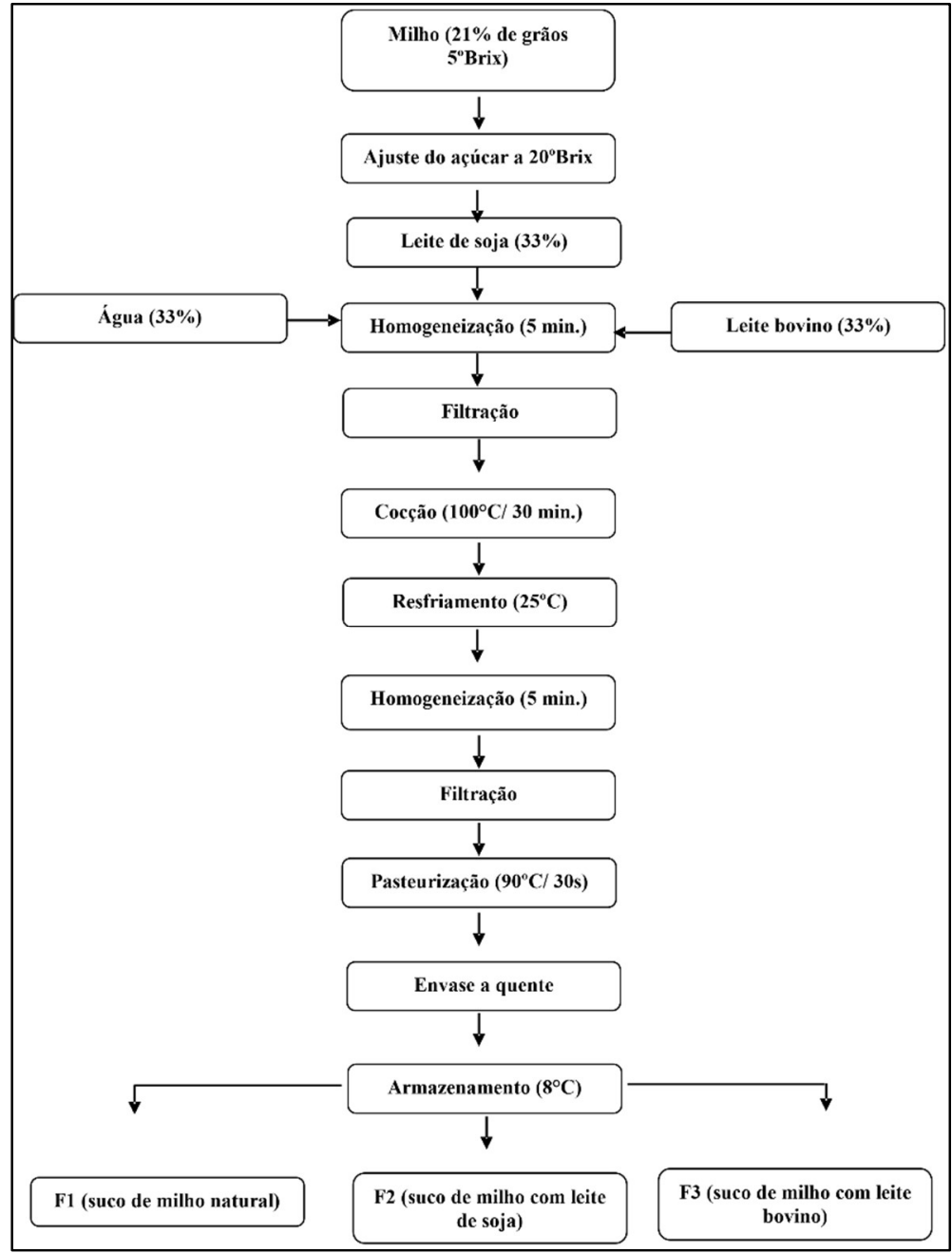

Figura 1: Fluxograma dos processos de produção dos sucos de milho.

\section{Análises microbiológicas}

As análises microbiológicas foram realizadas (em triplicata) nos grãos de milho e nos produtos elaborados, segundo recomendações e exigências da RDC n. 12 (ANVISA, 2001), para fungos filamentosos e leveduras, Salmonella spp., Coliformes a $35^{\circ} \mathrm{C}$ e a $45{ }^{\circ} \mathrm{C}$ e Staphylococcus coagulase positiva de acordo com Silva et al. (2001).

\section{Análise sensorial dos sucos de milho elaborados}

A avaliação sensorial foi realizada na Universidade Federal Rural da Amazônia no Campus de Parauapebas, no mês de maio de 2019, por 100 provadores não treinados, selecionados aleatoriamente, de ambos os sexos, com faixa etária de 10 a 60 anos, pertencentes a comunidade acadêmica da UFRA. Para cada avaliador foi entregue aproximadamente $30 \mathrm{~mL}$ das formulações de suco de milho refrigeradas a $8 \stackrel{\circ}{ } \mathrm{C}$, 
servidas em copinhos descartáveis (de $50 \mathrm{~mL}$ ) codificados com números de três dígitos aleatórios, um copo com água (de $150 \mathrm{~mL}$ ) e bolacha água e sal limpar as papilas gustativas e não interferir na análise sensorial, sendo-Ihe solicitado avaliar cada amostra, individualmente, quanto a aparência, aroma, sabor e impressão global (modo geral do produto), com uma escala hedônica de nove pontos, ancorados em seus extremos nos termos gostei muitíssimo (9) e desgostei muitíssimo (1) (Figura 2) (ABNT, 2014; DUTCOSKY, 2007; STONE et al., 1993). Em seguida, foi solicitada a avaliação dos produtos quanto ao teste de intenção de compra, a fim de verificar se o produto seria bem comercializado ou não, com uma escala hedônica de 5 pontos (Figura 2), de acordo com o método de Dutcosky (2007).

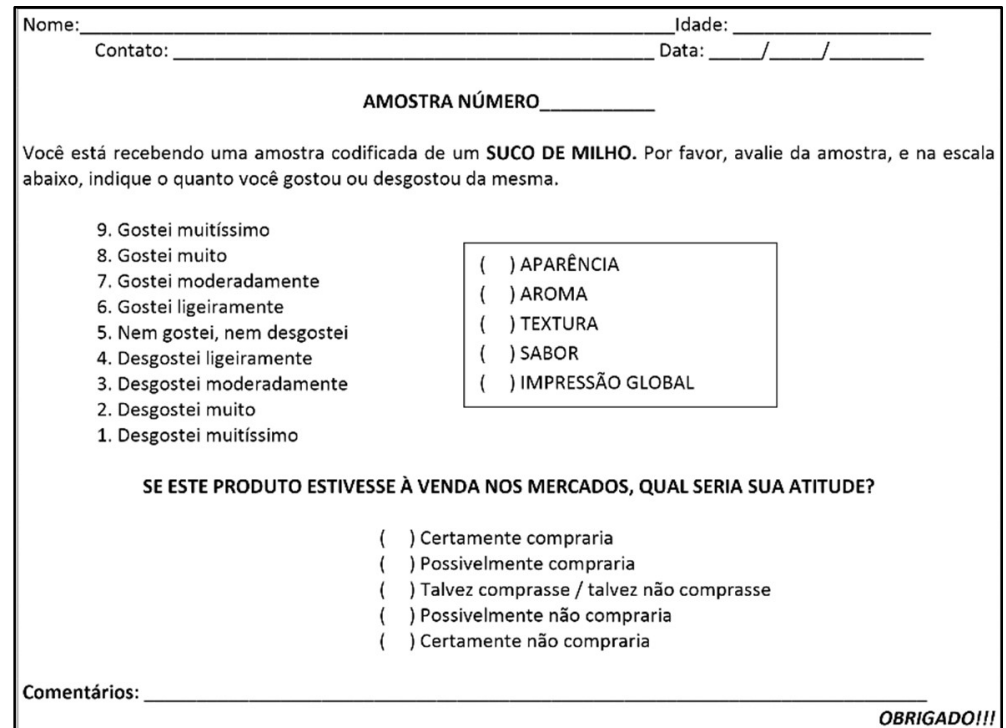

Figura 2: Questionário utilizado na avaliação do perfil de provadores no teste de aceitação.

\section{Análise estatística dos resultados}

Os resultados das análises sensoriais dos sucos de milho elaborados foram avaliados através das médias submetidas à análise de variância, e quando apresentaram diferenças foram comparadas pelo Teste de Tukey a $5 \%$ de $(p<0,05)$ probabilidade, utilizando-se o software SAS ${ }^{\circledR}$ versão 9.4 (SAS INSTITUTE, 2013).

\section{RESULTADOS E DISCUSSÃO}

\section{Análises microbiológicas}

Os resultados verificados nos grãos de milho e nos sucos elaborados, indicaram ausência de fungos filamentosos e leveduras, Salmonella spp., Coliformes 35 e a $45{ }^{\circ} \mathrm{C}$, Staphylococcus coagulase positiva, para $25 \mathrm{~g}$ de amostra. Portanto, de acordo com a resolução $n^{\circ} 12$, de 2 de janeiro de 2001, os grãos e os produtos estão dentro dos padrões determinados pela Resolução RDC, de 12 de janeiro de 2001, da Agência Nacional de Vigilância Sanitária (ANVISA,2001).

\section{Avaliação sensorial dos sucos de milho produzidos}

Perfil dos provadores quanto ao sexo e faixa etária. Na Figura 3 pode ser observada a porcentagem dos provadores por sexo e faixa etária. Participaram da avaliação 100 provadores não treinados e 
selecionados aleatoriamente, dentre estes, $64 \%$ representavam o público feminino e $36 \%$ o público masculino. A idade dos provadores que participaram da sensorial foi de 10 a 60 anos, dividindo-se de três formas 10 a 20, de 20 a 40 e 40 a 60 anos. Os percentuais encontrados para os três grupos são: 37, 60 e 3\% respectivamente. Na Tabela 1 podem ser observadas as médias para os atributos sensoriais avaliados nas três formulações de milho produzidas.

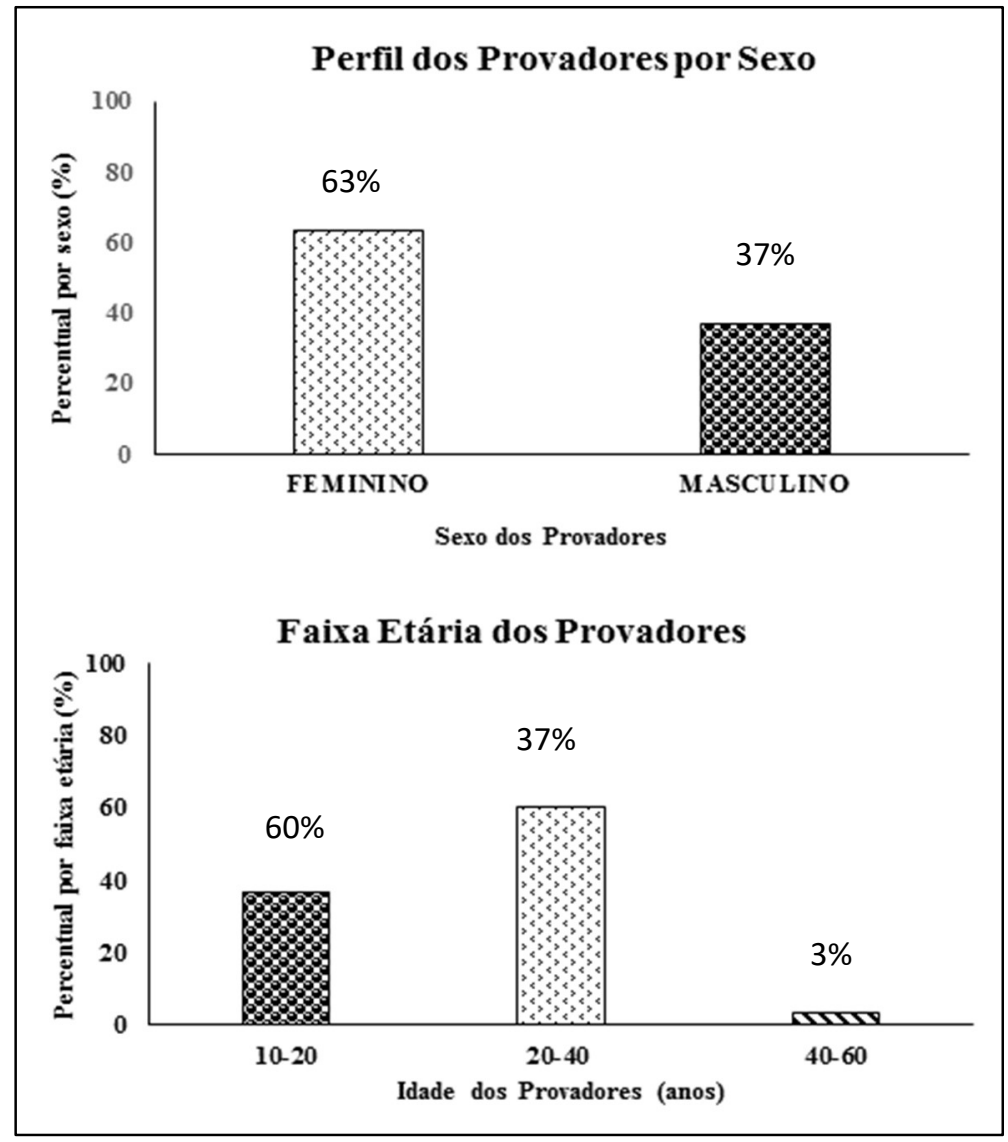

Figura 3: Porcentagem dos provadores por sexo e faixa etária.

Tabela 1: Avaliação sensorial dos sucos de milho formulados.

\begin{tabular}{|c|c|c|c|c|c|}
\hline \multirow{2}{*}{\multicolumn{2}{|c|}{$\begin{array}{l}\text { Produto/ } \\
\text { Formulações }\end{array}$}} & \multicolumn{4}{|c|}{ Atributo (média \pm desvio padrão) } \\
\hline & & Aparência & Aroma & Sabor & Impressão Global \\
\hline \multirow{3}{*}{$\stackrel{\stackrel{\Xi}{n}}{n}$} & F1 & $6,80 \pm 0,83^{b}$ & $6,57 \pm 1,10^{b}$ & $5,87 \pm 1,22^{b}$ & $6,15 \pm 1,10^{b}$ \\
\hline & F2 & $6,87 \pm 1,07^{b}$ & $6,89 \pm 1,03^{b}$ & $6,37 \pm 1,27^{b}$ & $7,07 \pm 1,06^{a}$ \\
\hline & F3 & $7,56 \pm 1,00^{a}$ & $7,67 \pm 1,12^{\mathrm{a}}$ & $7,58 \pm 0,97^{a}$ & $7,56 \pm 1,00^{a}$ \\
\hline \multicolumn{2}{|l|}{$D M S$} & 0.5987 & 0,6685 & 0,7139 & 0,6493 \\
\hline \multicolumn{2}{|l|}{ F calc. } & $5,62^{n s}$ & $8,13^{n s}$ & $17,39^{\text {ns }}$ & $13,82^{\text {ns }}$ \\
\hline \multicolumn{2}{|l|}{$C V$} & 13,74 & 15,42 & 17,55 & 15,22 \\
\hline
\end{tabular}

F1: suco de milho natural; F2: suco de milho com leite de soja e F3: suco de milho com leite bovino. DMS - Diferença mínima significativa; médias seguidas pela mesma letra na coluna não diferem estatisticamente entre si pelo teste de Tukey ao nível de $5 \%$ de probabilidade; ns - não significativo; * - significativo ao nível de 5\% de probabilidade. Os valores representam a média \pm desvio padrão de 100 provadores $(n=100)$.

Para o atributo aparência, os sucos compostos de milho apresentaram uma boa aceitação por parte dos provadores. Estes atribuíram a nota média 6,80 para a formulação F1 (Suco de milho), 6,87 para a formulação F2 (Suco de milho com soja) e 7,56 para a formulação F3 (suco de milho com leite). As médias estiveram entre 6 e 7, indicando que os sucos foram classificados como "gostei ligeiramente" a "gostei moderadamente". As bebidas com maior proporção de extrato hidrossolúvel de soja, apresentaram, visualmente, coloração mais intensa. Pode-se observar na Tabela 1 que a preferência dos provadores pelas 
bebidas não tem uma relação direta com a intensidade de cor (ULIANA et al., 2012).

Com relação aos valores médios obtidos para o atributo aroma, as formulações de sucos F1 (Suco de milho), F2 (Suco de milho com soja) e F3 (Suco de milho com leite) (Tabela 1) não ficaram muito distantes dos valores de médias encontrados por Brunelli et al. (2012) $(6,02$ e 6,82) ao fazer a análise sensorial das bebidas mistas de soja e suco de uva. Rodrigues (2003) obteve valores ligeiramente inferiores $(5,92$ e 6,67) para o atributo aroma em bebidas formuladas com extrato hidrossolúvel de soja e polpa de pêssego. Mas, Soares Júnior et al. (2009) produziram bebidas de extrato de soja com polpa de maracujá e açúcar, e alcançaram valores superiores ao conseguido neste trabalho (7,92 - gostei muito) para o atributo aroma.

O sabor é um dos atributos mais importante na análise sensorial, pois é através dele que se pode classificar a escolha do consumidor na hora de adquirir o produto. Esses resultados podem ser explicados pelo sabor que o leite de soja e o leite bovino incorporaram ao suco de milho, levando os avaliadores optar pela formulação F2 (Suco de milho com soja) e F3 (Suco de milho com leite) em detrimento da formulação F1 (Suco de milho) (Tabela 1).

Borges et al. (2011) observaram em seu experimento valores relacionados ao atributo sabor bem próximos ao deste referido trabalho. Foram feitas analises sensoriais em seis sucos de uva e observado valores que ficaram entre 6,56 e 7,02. Pode ser observado que sua menor média foi superior a menor média desse estudo, já sua maior média foi inferior a maior média deste referido trabalho.

A impressão global é o conjunto relativo da impressão causada pelo produto como um todo ao avaliador. Sendo assim, as formulações que se destacaram com os maiores valores médios atribuídos pelos provadores, foram a F2 (7,07 - Suco de milho com soja) e F3 (7,56 - Suco de milho com leite) e o menor valor apresentado foi para a formulação F1 (6,15 - Suco de milho). Esses valores médios ficaram próximos ao entrados por Borges et al. (2011) que foi de 6,74 a 7,30 com relação a impressão global.

\section{Intenção de compra dos produtos}

Através da Figura 4 pode ser observada a intenção de compra para os sucos de milho formulados. Na Figura 4, os valores demostraram que no ato da atitude de compra dos potenciais consumidores, as formulações F2 (Suco de milho com soja) e F3 (Suco de milho com leite) obtiveram resultados mais elevados nos índices de aceitação por parte dos avaliadores, com percentuais de 19,98\%; e 36,63\%, respectivamente os quais 'certamente comprariam' (CC) os produtos. Tal comportamento deve ser justificado, uma vez que as formulações possuem em sua composição o leite de soja e leite bovino, o que agradou o paladar dos provadores.

Pontes et al. (2010) ao avaliarem a aceitação de sucos de uva comerciais, observaram que o suco integral de uva apresentou maior intenção de compra (78\% possivelmente comprariam ou certamente comprariam), seguido do néctar de uva (63\%) e do suco concentrado de uva (15\%). Valores estes, próximos aos avaliados neste trabalho. Souza et al. (2011) também verificaram resultados próximos aos obtidos no presente estudo, logo a porcentagem de provadores que "provavelmente e certamente comprariam" o produto variou de 30 a 74,35\% ao realizarem o teste de intenção de com polpas de laranja Pêra. 


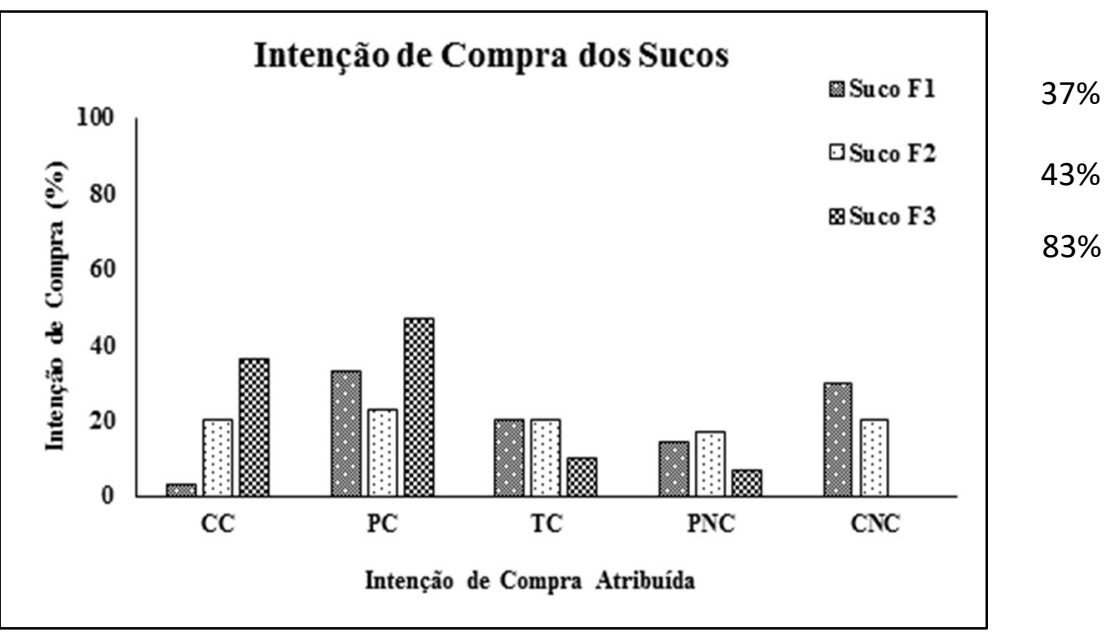

Figura 4: Intenção de compra para os sucos de milho formulados.

Suco F1: suco de milho natural; Suco F2: suco de milho com leite de soja e Suco F3: suco de milho com leite bovino. CC (Certamente Compraria), PC (Possivelmente Compraria), TC (Talvez Compraria), PNC (Possivelmente Não Compraria) e CNC (Certamente Não Compraria).

\section{CONCLUSÕES}

Quanto as análises microbiológicas realizadas nos grãos de milho e nos sucos de milho, as mesmas estiveram dentro dos padrões exigidos pela legislação vigente, refletindo, assim, a qualidade higiênica do processamento. Todos os parâmetros avaliados no teste de aceitação sensorial (aparência, aroma, sabor e impressão global) dos sucos de milho, obtiveram notas médias entre 5 (gostei ligeiramente) e 7 (gostei moderadamente), indicando aceitação dos produtos por parte dos provadores. Logo os sucos de milho compostos com leite de soja e leite bovino, apresentaram uma melhor aceitação pelo público em geral. Enquanto que, o suco de milho natural não foi bem aceito pelos mesmos. Através dos estudos sensoriais realizados, pode-se observar que o suco de milho se apresentou como uma alternativa tecnológica viável para a agricultor familiar do município de Parauapebas/PA.

\section{REFERÊNCIAS}

ABNT. Associação Brasileira de Normas Técnicas. NBR ISO 5492:2014: Análise sensorial dos alimentos e bebidas: terminologia. São Paulo: ABNT, 2014.

ANVISA. Agência Nacional de Vigilância Sanitária. Resolução RDC n. 12 de 02 de janeiro de 2001. Dispõe sobre o regulamento técnico sobre padrões microbiológicos para alimentos. Brasília: DOU, 2001.

ANVISA. Agência Nacional de Vigilância Sanitária. Resolução RDC n. 259, de 20 de setembro de 2002. Dispõe sobre o regulamento técnico para rotulagem de alimentos embalados. Brasília: DOU, 2002.

BORGES, I. D.; VON PINHO, R. G.; PEREIRA, J. L. A. R.; ALVAREZ, C. G. D.. Efeito das épocas de aplicação da cobertura nitrogenada, das fontes de nitrogênio e dos espaçamentos entre fileiras na cultura do milho. Revista Ceres, Lavras, v.53, p.75-81, 2006.

BORGES, R. S.; PRUDÊNCIO, S. H.; ROBERTO, S. R.; ASSIS, A. M.. Avaliação sensorial de suco de uva cv. Isabel em cortes com diferentes cultivares. Revista Brasileira de Fruticultura Jaboticabal, v.33, p.584-591, 2011. DOI: http://dx.doi.org/10.1590/S0100-29452011000500080

BRUNELLI, L. T.; VENTURINI FILHO, W. G.. Caracterização química e sensorial de bebida mista de soja e uva. Revista de Alimentos e Nutrição, Araraquara, v.23, n.3, p.467-473. 2012.

DUTCOSKY, S. D.. Análise Sensorial de Alimentos. 2 ed. Curitiba: Champagnat, 2007.

EMBRAPA. Empresa Brasileira de Pesquisa Agropecuária. Sistemas de Produção: Cultivo do milho. 5 ed. Brasília: EMBRAPA, 2009.

FAO. Food and Agriculture Organization of the United Nations. FAOSTAT. FAO, 2018.

GONÇALVES, A. R.; DINNOUTI, L. A.; ARAÚJO, R. M.; COSTA, F. O.; SANTIIAGO, T.. Manual de armazenamento de produtos fitossanitários/agrotóxicos. São Paulo: ANDEF, 
2005.

KITAMURA, P. C.; IRIAS, L. J. M.. O profissional de pesquisa \& desenvolvimento rural para os novos tempos. Cadernos de Ciência \& Tecnologia, v.19, n.1, p.119-134, 2002.

MAPA. Ministério da Agricultura, Pecuária e Abastecimento. Decreto n. 2.314, de 04 de setembro de 1997. Regulamenta a Lei $n .8 .918$, de 14 de julho de 1994, que dispõe sobre a padronização, a classificação, o registro, a inspeção, a produção e a fiscalização de bebidas. Brasília: MAPA, 1997.

MARCHI, S. L.. Interação entre desfolha e população de plantas na cultura do milho na Região Oeste do Paraná Dissertação (Mestrado em Agronomia) - Universidade Estadual do Oeste do Paraná, Marechal Cândido Rondon, 2008.

NEUMANN, M.; OST, P. R.; LUSTOSA, S. B. C..

Comportamento produtivo de híbridos de milho (Zea mays L.) e sorgo (Sorghum bicolor) para produção de silagem. In: REUNIÃO ANUAL DA SOCIEDADE BRASILEIRA DE ZOOTECNIA, 43. Anais. João Pessoa: Sociedade Brasileira de Zootecnia, 2006.

PALLET, D.; CABRAL, L.; MATTA, V.; PEZOA-GARCÍA, N. H.; MENEZES, H. C.; ABREU, F. A. P.; DORNIER, M.; REYNES, M.. Aplicação da Tecnologia de membranas no Processamento de sucos de frutas Brasileiras. Caderno de Ciência e Tecnologia, Brasília, v.22, n.2, p.427-437, 2005.

PAVAN, T. A.; NEVES, M. F.; CARVALHO, D. T.. O Processo de compra de suco de laranja por varejistas. Abecitrus, 2006.

PEREIRA, B.. Processamento agrega valor: Frutas e derivados. São Paulo: Publicação Trimestral do IBRAF, 2006.

PONTES, P. R. B.; SANTIAGO, S. S.; SZABO, T. N.; TOLEDO, L. P.; GOLLÜCKE, A. P. B.. Atributos sensoriais e aceitação de sucos de uva comerciais. Ciência e Tecnologia de Alimentos, Campinas, v.30, n.2, p.313-318, 2010.

RODRIGUES, R. S.. Caracterização de Extrato de Soja Obtido de Grãos, Farinha Integral e Isolado Proteico Visando à Formulação e Avaliação Biológica (em Coelhos) de Bebida Funcional à Base de Extrato de Soja e Polpa de Pêssegos. Tese (Doutorado em Tecnologia de Alimentos) Universidade Estadual de Campinas, Campinas, 2003.

ROSA, S. E. S.; COSENZA, J. P.; LEÃO, L. T. S.. Panorama do Setor de Bebidas no Brasil. BNDES Setor, 2006.

SAS INSTITUTE. SAS for Windows, versão 9.4 SAS ${ }^{\circledR}$ : SAS User guide. Carry, 2013.

SILVA, N.; JUNQUEIRA, V. C. A.; SILVEIRA, N. F. A.. Manual de métodos de análise microbiológica de alimentos. $2 \mathrm{Ed}$. São Paulo: Varela, 2001.

SOARES JÚNIOR, M. S.; REIS, R. C.; BASSINELLO, P. Z.; LACERDA, D. B. C.; KOAKUZU, S. N.; CALIARI, M.. Qualidade de biscoitos formulados com diferentes teores de farinha de casca de pequi. Pesquisa Agropecuária Tropical, Goiânia, v.39, n.2, p.98-104, 2009.

SOUZA, A. L. G.; MOURA, A. S.; CARNELOSSI, M. A. G.; CASTRO, A. A.. Avaliação dos níveis de Aceitação e de Intenção de compra da polpa de laranja Pêra congelada e criocongelada. Scientia Plena, v.7, n.3, p.1-8, 2011.

STONE, H. S.; SIDEL, J. L.. Sensory Evaluation Practies. 2 Ed. San Diego: Academic Press, 1993.

STRIEDER, M. L.. Resposta do milho à redução do espaçamento entrelinhas em diferentes sistemas de manejo. Dissertação (Mestrado e Fitotecnia) - Universidade Federal do Rio Grande do Sul, Porto Alegre, 2006.

ULIANA, M. R.; VENTURINI FILHO, W. G.; ULIANA, L. R.. Nota Científica: Teste de aceitação de bebida mista de soja e amora. Universidade Estadual Paulista, Campinas, v.15, n.2, p.174-181, 2012.

WANDERLEY, M. N. B.. O mundo rural como um espaço de vida. Porto Alegre: UFRGS, 2009.

A CBPC - Companhia Brasileira de Produção Científica (CNPJ: 11.221.422/0001-03) detém os direitos materiais desta publicação. Os direitos referem-se à publicação do trabalho em qualquer parte do mundo, incluindo os direitos às renovaç̃oes, expansões e disseminações da contribuiç̃o, bem como outros direitos subsidiários. Todos os trabalhos publicados eletronicamente poderão posteriormente ser publicados em coletâneas impressas sob coordenação da Sustenere Publishing, da Companhia Brasileira de Produção Científica e seus parceiros autorizados. Os (as) autores (as) preservam os direitos autorais, mas não têm permissão para a publicação da contribuição em outro meio, impresso ou digital, em português ou em tradução. 